\title{
Optimal Combination of Currency Assets and Algorithm Simulation under Exchange Rate Risk
}

\author{
Jun Wei (iD \\ College of Marxism, Minnan Normal University, Zhangzhou 363000, China \\ Correspondence should be addressed to Jun Wei; weijun520@mnnu.edu.cn
}

Received 19 September 2020; Revised 10 October 2020; Accepted 20 October 2020; Published 2 November 2020

Academic Editor: Wei Wang

Copyright ( 2020 Jun Wei. This is an open access article distributed under the Creative Commons Attribution License, which permits unrestricted use, distribution, and reproduction in any medium, provided the original work is properly cited.

\begin{abstract}
The excess money supply did not lead to a rapid rise in the price index, which in turn triggered inflation. In this case, the redetermination of the demand for money is particularly important. At the same time, with the continuous expansion of the capital market and the rapid development of the virtual economy, the virtual economy is gradually deviating from the real economy. When selecting assets, microentities often incorporate virtual economic assets into investment considerations. Therefore, it is necessary to establish a money demand model that considers the impact of virtual economic assets. This paper uses the asset selection of microentities as the microfoundation to establish a money demand model to explain its economic significance. And based on the money demand model established, a dynamic equilibrium model of the money market was established, and the stability of the dynamic equilibrium point of the money market was verified through mathematical deduction. Based on the dynamic equilibrium model of the money market, the impact of money supply was analyzed. In order to verify the correctness of the aforementioned theory, this paper conducts an empirical analysis. Through cointegration analysis and the vector error correction model (VECM model), the correctness and applicability of the established money demand model are verified, and money demand, total social wealth, spreads between expected stock returns and interest rates, and real estate expectations are found. There is a long-term equilibrium relationship between the rate of return and the interest rate. The total amount of social wealth, the expected rate of return on stocks, and the interest rate spread will have an impact on the demand for money in the short term.
\end{abstract}

\section{Introduction}

The foundation of the modern monetary theory is the asset selection theory [1]. From the perspective of the asset allocation of economic actors, scholars have considered the willingness of microagents to hold currency assets and estimated the macro-money demand function based on the money demand of microagents $[2,3]$. Keynes first established a money demand model based on the perspective of the asset selection of microsubjects. Based on residents' speculative money demand for bonds and currencies, he proposed a liquidity-preference money demand model. Hicks took the lead in putting forward the basic principles of the asset selection theory, that is, considering the demand for money from the perspective of asset allocation. In the presence of risks, in order to maximize returns, microentities choose to use their own wealth in different types of assets [4].
Based on Markowitz's asset portfolio theory, previous work puts forward the idea of analyzing money demand by determining the proportion of assets that residents choose to hold in order to maximize utility under certain risks. Based on the aforementioned theory, the macroperformance of the macro-money demand of the microbody's choice of money assets can be based on the money demand of the microbody to construct a macro-money demand model [5-9].

Therefore, when constructing the money demand model, we can learn from the asset selection theory put forward by previous scholars, take the asset selection behavior of microentities as the microbasis of money demand, and regard money as an asset held by microentities, and consider the assets and prices held by micro entities in other forms fluctuate randomly, using random variables to obtain the money demand model of the microentities, and use this to estimate the macro-money demand model [10]. Many 
domestic scholars have adopted this method to estimate the money demand model. The accuracy of the traditional money demand equation is not in the past [11]. This is specifically manifested in the aftermath of the financial crisis; the money supply is much higher than the theoretical money supply calculated according to the Western money quantity theory formula, and this part of the "excess" money supply shows an upward trend. According to the traditional quantity theory of money, the money supply increases, and the price index rises, which in turn triggers inflation. In recent years, the macroeconomy has shown a deflationary trend [12-15]. A large amount of "excess" money supply and low price index coexist. The traditional quantity theory of money becomes invalid at this time. This problem is called "currency" by mckinnon mystery'. This phenomenon shows that when faced with an increase in the nominal income of the same scale, microeconomic entities choose to hold more monetary assets. Therefore, to explain the so-called " currency mystery," it is necessary to understand the reasons for the rising demand for money from microeconomic entities [16]. In this case, it is particularly important to remeasure the demand for money, as shown in Figure 1. Focusing on the theme of remeasurement of money demand and comprehensively considering the residents' motivation to hold assets and the influence of virtual economic assets on money demand, a new money demand model is established from the perspective of micro-main asset selection [17]. In recent years, capital market has continued to develop, and capital holding forms have gradually diversified. The two most important assets held by residents are stocks and real estate. The high-yield characteristics of stocks attract more and more investors to enter the market [18]. With the continuous appreciation of real estate, a large amount of capital is attracted to the real estate market. Microsubjects choose to hold real estate more for investment motivation, not just for housing [19]. The real estate at this time more reflects the attributes of its investment, with the nature of virtual economy [20]. At the same time, with the rapid development of the virtual economy market and the gradual separation of the real economy, a large number of asset bubbles have emerged in the real estate market and stock market, and the macroeconomic environment has accelerated and complicated, which has also had a great impact on the demand for money [21].

Changes in the money supply will have a strong impact on real estate prices. In recent years, housing prices have risen rapidly. This is closely related to the increase in the population and monetary easing policy. This not only brings hidden dangers to the smooth operation of the macroenvironment but also brings more pressure to residents. Therefore, in the monetary policy implementation, we believe that it is necessary to fully control the implementation of the monetary policy in order to prevent the impact of excessive policy control on real estate prices and to reduce the formation of bubbles in the real estate market. At the same time, we need to promote effective implementation of regulatory policies in the real estate market, regulate superheated housing demand and housing prices, increase the effective supply of the real estate, and correct and create a violation of discipline and regulation in the real estate market and a sound and good real estate trading environment. This paper uses the asset selection of microentities as the microfoundation to establish a money demand model to explain its economic significance. And based on the money demand model established, a dynamic equilibrium model of the money market was established, and the stability of the dynamic equilibrium point of the money market was verified through mathematical deduction. Based on the dynamic equilibrium model of the money market, the impact of money supply was analyzed. Dynamic influence: in order to verify the correctness of the aforementioned theory, this paper conducts an empirical analysis. Through cointegration analysis and the vector error correction model (VECM model), the correctness and applicability of the established money demand model are verified, and money demand, total social wealth, spreads between expected stock returns and interest rates, and real estate expectations are found. There is a long-term equilibrium relationship between the rate of return and the interest rate. The total amount of social wealth, the expected rate of return on stocks, and the interest rate spread will have an impact on the demand for money in the short term.

\section{Construction of the Currency Asset Portfolio Model for the Exchange Rate Risk}

2.1. Asset Selection Theory. The basis of the modern monetary theory is the asset selection theory as shown in Figure 2. From the perspective of the asset allocation of economic actors, Western scholars consider the willingness of microagents to hold currency assets and estimate the macro-money demand function based on the money demand of microagents. Keynes first established a money demand model based on the perspective of the asset selection of microsubjects. Based on residents' speculative money demand for bonds and currencies, he proposed a liquiditypreference money demand model. Hicks led the basic principle of the asset choice theory to consider the demand for money from the perspective of asset allocation. If the risk exists, the microentity selects to use its own wealth in various types of assets to maximize return. Based on Markowitz's asset portfolio theory, Tobin advocated the idea of analyzing the demand for money by determining the proportion of assets that residents choose to maximize utility under certain risks. Based on the above theory, the macroperformance of macro-money demand for microbody money asset selection can be based on micro-money demand to build macromoney demand models.

Therefore, in order to construct the demand model of Japan, we can learn from the asset choice theory advocated by foreign scholars and utilize the asset selection behavior of the microsubject as a microbasis of the demand for money, and it can be regarded as holding assets. Microsubject: a stochastic demand method is used to obtain a monetary demand model for microentities, taking into account random fluctuations of assets and prices held by other microentities. Many scholars have adopted this method to estimate the money demand model. Starting from the 


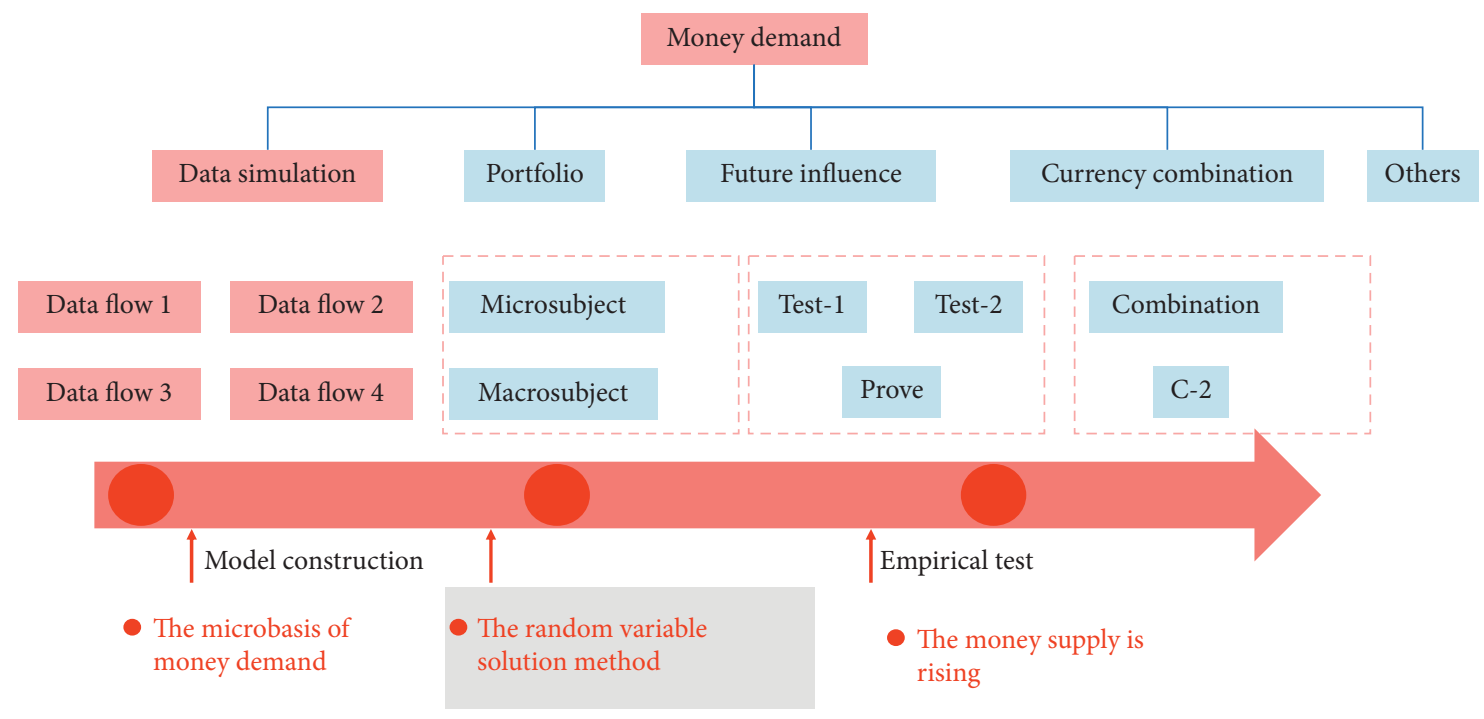

FIgURE 1: Schematic diagram of the concept of the copula model.

optimal behavior of residents, they have constructed a real money demand function considering the security market.

$$
\frac{N}{P}=n_{m} W e^{\left(1-n_{m}\right) r-n_{m} \pi-c / W} t .
$$

2.2. Tobin's Portfolio Theory. Tobin divides the assets that residents can choose to hold into two categories: one is monetary assets, which are characterized by high liquidity, risk-free, and stable value, and the other is nonmonetary assets held in other forms, such as interest-bearing assets or physical assets. Such assets generally have the characteristics of high risk and high return. Residents consider the proportion of assets they choose to hold in order to maximize utility under certain risks. The following assumptions exist:

(1) In daily life, residents can only choose to hold currency and bonds; the amount of currency held is $n$, the amount of bonds held is $b$, the bond price is $p$, and the total amount of wealth held by residents is

$$
k=n+p b .
$$

(2) The proportion of residents choosing to hold currency assets is $A_{1}$, and the proportion of holding bond assets is $A_{2}, A_{1}+A_{2}=1$. All residents in the economy are risk aversions and will have the expectation of risk aversion. In the case of maximizing the utility of income, choose the ratio of holding currency and bonds.

(3) The return of holding currency is 0 , the annual fixed rate of return of the bond is $r$, and the capital gain or loss it brings is $g$; when the expectation of future returns is uncertain, the total return of the asset portfolio can be expressed. Therefore, based on the random walk theory, $g$ is a random variable with a mean value of 0 , and the expected return rate of the asset portfolio is

$$
R=A_{1}+A_{2}(r+g) .
$$

Here, we suppose the risk of the asset portfolio is $a$. Assuming that the bond issuer has been operating stably, the annual fixed income of the bond is risk-free, and the risk of capital gains and losses of the bond is $g, a=a_{2} g$.

$$
A_{2}=\frac{E(R)}{r}=\frac{a}{g}
$$

When the annual fixed rate of return $r$ of the bond and the risk of capital gains and losses $g$ are constant, the return of the asset portfolio is proportional to the risk. The function to determine the optimal point of the asset portfolio is shown in Figure 3, where $\mathrm{OC}$ is the relationship curve reflecting the expected return rate of the asset portfolio $E(R)$ and the asset portfolio risk $a$.

\section{Application of the Currency Portfolio Theory}

3.1. Impact of Other Assets. The type of property held by residents is diverse and extensive. The estimated monetary demand model for Tobin's microsubject considers only two financial assets of the currency and the bond and ignores the investigation of other assets. Even if other models of noncash assets are added to Tobin's model, the way of analyzing the problem will not change. The following are the assumptions:

(1) In daily life, residents can choose to hold currency and $m$ types of nonmonetary assets; the total wealth held by residents is $W$. Assuming that there is no risk in holding currency, inflation is not considered.

(2) The proportion of residents who choose to hold currency is $A_{0}$, and the proportion of holding the $i$-th nonmonetary asset is $A_{i}$. All residents in the 

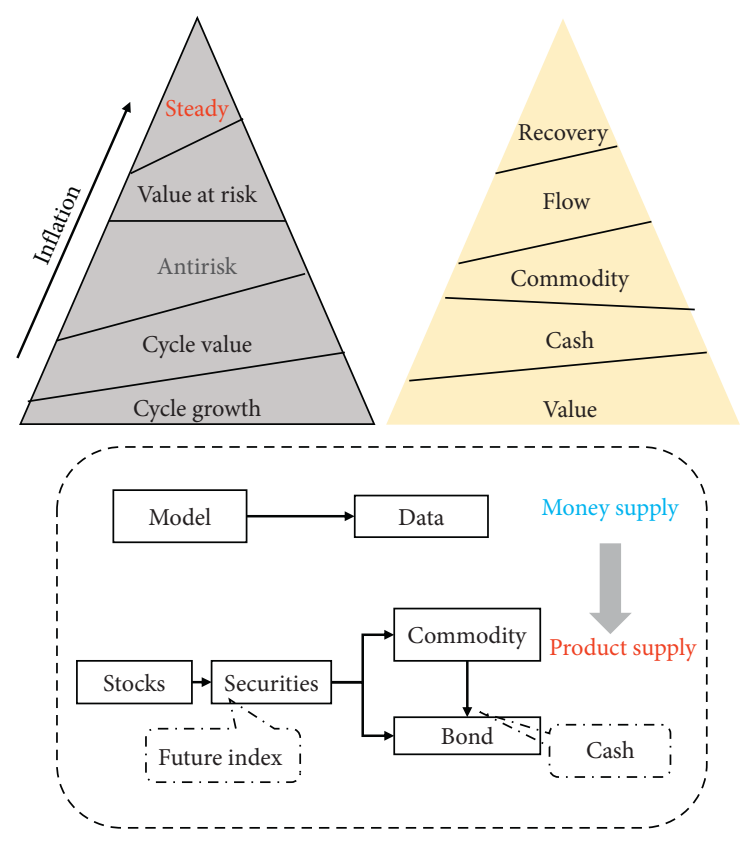

Figure 2: Asset selection theory.

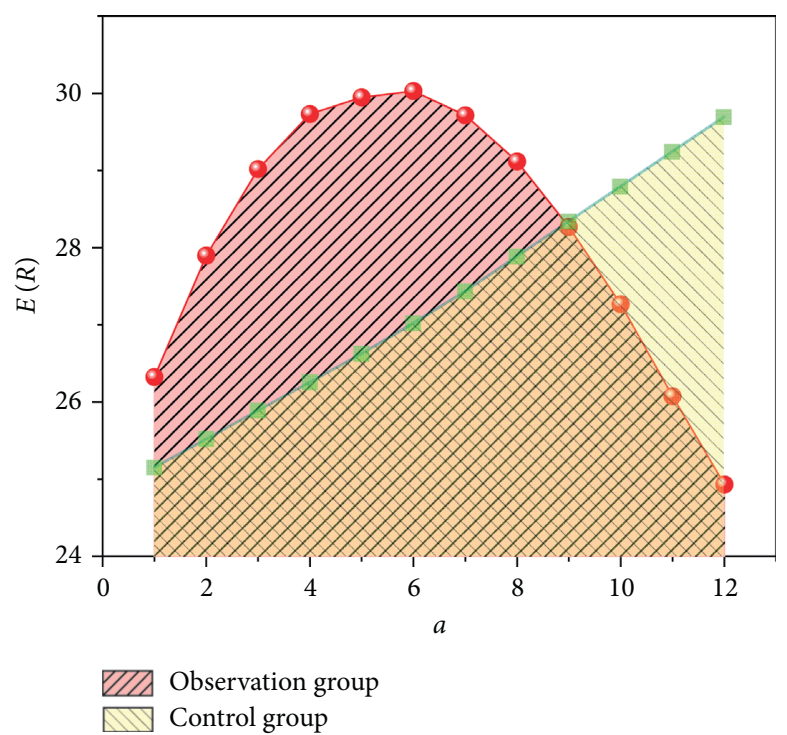

Figure 3: The function of the optimal point of the currency asset portfolio.

economy are risk aversers. Under the condition of maximizing the expected return utility with riskaversion characteristics, choose to hold various asset ratios.

(3) The return of holding currency is 0 , the return on assets of holding the $i$-th nonmonetary asset is $r_{i}$, and the capital gain or loss it brings is $g_{i}$.

(4) $V_{i j}(i$ is not equal to $j$ ) represents the covariance of the $i$-th and $j$-th nonmonetary asset returns, and $\mathrm{Vij}$ ( $\mathrm{i}$ is equal to $j$ ) represents the $i$-th asset. The variance of the return on nonmonetary assets; the total expected return on the asset portfolio is

$$
E(R)=\frac{\sum A_{a} r_{i}}{g}
$$

The total risk of the portfolio is

$$
a=\sum_{i=1}^{m} \sum_{i=1}^{m} r_{i j} E(R .)
$$

$E(R)$ and $a$ constitute the feasible set of residents' asset portfolio. According to von Neumann-Morgenstern's expected utility theory, when choosing behaviors based on risk 
and uncertainty, decisions are made according to the maximum expected return criterion (that is, the pros and cons of various investment options are compared based on the expected return on investment (decision-making)), with certain rationality and accuracy. Therefore, this article maximizes the expected utility of the portfolio of assets held by residents to determine the proportion of various assets held by residents.

$$
\left\{\begin{array}{c}
E(U)=E\left(U(E), a^{2}\right) \\
E(R)=\sum A_{i} r_{i} \\
a=\sum_{i=1}^{m} \sum_{j=1}^{m} a_{i j} A_{i} \\
\sum A_{i}=1
\end{array}\right\} \longrightarrow \leftarrow_{i=t}\left(A_{0}, A_{1} \ldots A_{n}\right) .
$$

Among them, $U$ is the utility function, and the rate of return of each asset in the rate of return expression is the expected rate of return of assets of the residents. By calculating the ratio of the monetary assets of microagents to the total wealth, we can determine the money demand of microagents in my country.

3.2. Asset Selection Behavior of Microsubjects. The asset selection behavior of microentities is the use of wealth for the purposes of preservation and profit generation. Therefore, there are three directions for residents to use wealth. One is to buy profit-generating financial assets, the other is to purchase assets with the characteristics of value preservation, and the third is to hold them in currency. Among them, profit-generating financial assets are financial assets such as bonds, stocks, and options. Assets with hedging properties mainly refer to real estate. Starting from my country's current economic conditions, the nonmonetary assets held by residents are mainly stocks and real estate. Therefore, this article only considers three assets: currency, stocks, and real estate (the currency here is defined as a narrow currency $M_{1}$, that is, cash in circulation plus savings deposits.). That is to say, my country's microsubjects will choose the asset portfolio of currencies, stocks, and real estate based on the principle of maximizing utility under the established risk preference. Among them, the two assets of stocks and real estate are special because they have the characteristics of virtual economy.

The essential difference between the virtual economy and the real economy lies in its price system. The price system of the real economy is based on cost and technology support pricing, while the virtual economy is based on the capitalized pricing method. The pricing method of the virtual economy makes its market price more dependent on human psychological factors and has inherent volatility in operation. In the virtual economy market, the influence of market information on prices and the price sensitivity of products are higher than those of the real economy. According to Ma Huai's point of view, the pricing method of the virtual economy is based on people's expectations and confidence in the market, which is speculative, volatile, and frothy. The price formula of virtual economic assets is

$$
P=\frac{R(E)}{i} .
$$

$P$ is the price in the virtual market, $R(E)$ is the expected return judgment determined by market confidence, and $i$ is the discount rate. Due to the particularity of the price of the virtual economy, compared with the real economy, the prices of products in the virtual economy market are more likely to rise or fall, leading to a large amount of currency inflow or withdrawal, causing the redistribution of the amount of currency in the entire economy as shown in Figure 4. Virtual economy is a newly developed concept in recent years. Different scholars have different definitions of the market scope of the virtual economy. One of the most commonly used is the previously proposed definition: "the virtual economy in a broad sense refers to all economic activities except material production activities and all related labor services, and the virtual economy in a narrow sense refers only to all financial activities and real estate." Most of the research studies adopted Liu Junmin's narrow definition of virtual economy, which is to define virtual economy as the financial industry and real estate industry. From the perspective of pricing, real estate adopts capitalized pricing, which has the attributes of a virtual economy. According to the development of the current virtual economy, the stock market and the real estate market are two sectors that occupy most of the capital of the virtual economy. Therefore, this article adopts a mainstream view and defines the virtual economic market as a stock market and real estate market. This article adopts a narrow definition of real estate, taking into account the fact that the virtual economic attributes of the real estate industry are examined more closely, and the real estate is regarded as an asset that adopts capitalized pricing methods. Building structure attached to stock and real estate pricing methods follow the pricing principles of the virtual economy.

\subsection{The Impact of Different Assets on the Currency Demand.} With the rapid development of the stock market, security transactions account for an increasing proportion of the 


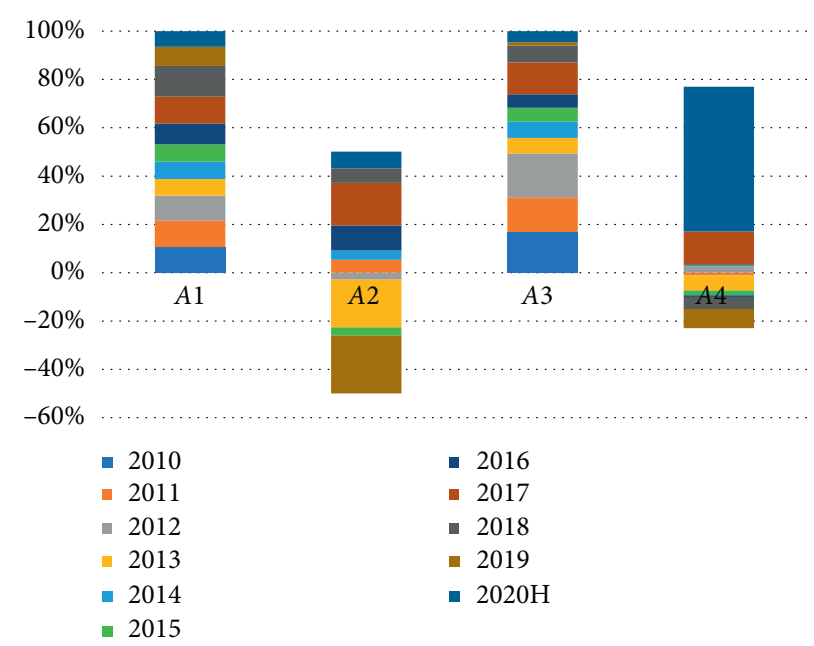

Figure 4: The circulation of money leads to the redistribution of the amount of money in the real economy.
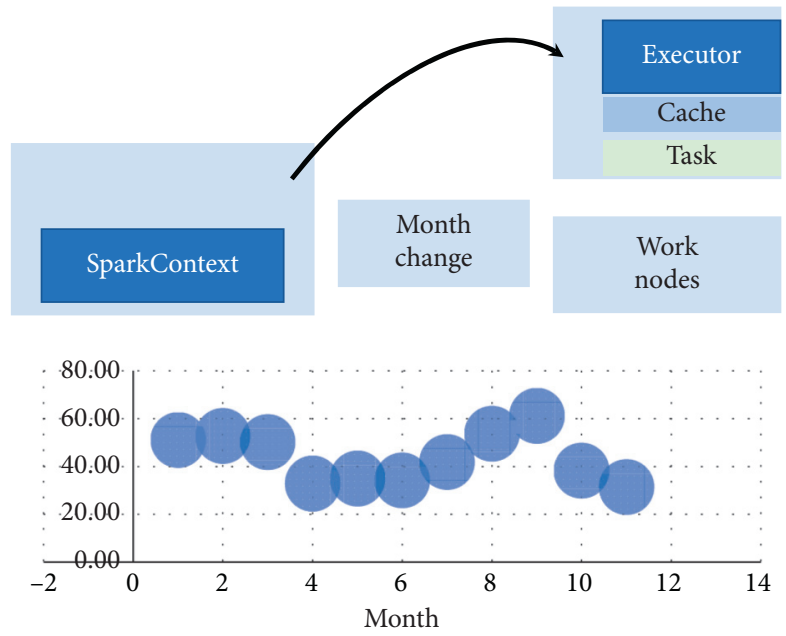

FIGURE 5: The impact of stocks on the money demand.

total economic system transactions. Stocks mainly affect the total money demand through four ways: wealth effect, asset portfolio effect, transaction effect, and substitution effect, as shown in Figure 5.

3.3.1. Wealth Effect. When stock prices rise, residents who hold stocks have more nominal wealth. While income remains stable, the ratio between the wealth held by residents and their income has risen, leading to an increase in residents' investment and consumer demand, which in turn generates more money demand. Conversely, when stock prices fall, the nominal wealth held by residents decreases, and the demand for investment consumpt. It has to be reduced, and the resulting currency demand also declines. The wealth effect of the stock market mainly affects the long-term money demand measured from the perspective of $M_{1}$. The influence mechanism of the wealth effect of stocks is stock price $\uparrow \longrightarrow$ nominal wealth $\uparrow$ investment, consumer $\quad$ demand $\uparrow \longrightarrow$ money demand $\uparrow$ stock price $\downarrow \longrightarrow$ nominal wealth $\downarrow \longrightarrow$ investment, consumer demand $\downarrow \longrightarrow$ money demand $\downarrow$.
3.3.2. Asset Portfolio Effect. Regarding currency as an asset, its rate of return is a negative inflation rate, which is $a$. When the volatility of stock prices increases, the risk of holding stocks increases, and the risk of the original investment portfolio expands. Under the circumstance that the residents' risk appetite does not change, the residents will spontaneously increase the proportion of lower-risk assets in the investment portfolio to offset the risk, that is, to increase the amount of money held in the hand, which increases the demand for money. When the volatility of stock prices decreases, the risk of holding stocks decreases, and the risk level of the original investment portfolio decreases. Under the circumstance that the risk appetite does not change, residents will spontaneously increase the riskiness of the investment portfolio. The proportion of assets increases income. The influence mechanism of the portfolio effect of stocks is stock price volatility $\uparrow \longrightarrow$ stock risk $\uparrow \longrightarrow$ investment portfolio risk $\uparrow \longrightarrow$ increasing the proportion of currency holdings to offset the risk $\uparrow \longrightarrow$ money demand $\uparrow$ stock price volatility $\downarrow \longrightarrow$ stock risk $\downarrow \longrightarrow$ investment portfolio risk 
$\downarrow \longrightarrow$ increase the proportion of high-risk and high-yield assets such as stocks to increase returns $\downarrow \longrightarrow$ money demand $\downarrow$.

3.3.3. Transaction Effect. The trading effect of the stock market on the currency demand can be explained from three aspects. On the one hand, residents have a large amount of direct transactional currency demand due to the purchase of stocks, which in turn drives the increase in the currency demand. On the other hand, as the price of stocks rises, more transactions are generated in the market, which require more currency to support the completion of transactions, thus driving the total demand for money. On the contrary, due to differences in information obtained by residents, or out of different understandings of information, even if the company's fundamentals have not changed, there are residents who expect future earnings to rise, and therefore choose to trade. The increase in the transaction volume has triggered an increase in the demand for money. At the same time, the increase in the stock trading volume may also lead to an increase in stock prices, thereby further expanding the demand for currency. The influencing mechanism of the trading effect of stocks is (1) stock trading $\longrightarrow$ money demand generated by the exchange; (2) stock price $\uparrow \longrightarrow$ transaction volume $\uparrow \longrightarrow$ money demand $\uparrow$ money demand $\uparrow$; (3) expected future return increase $\longrightarrow$ trading volume $\uparrow$ stock price $\uparrow \longrightarrow$ transaction volume $\uparrow \longrightarrow$ money demand $\uparrow$.

3.3.4. Substitution Effect. When the stock price rises, the attractiveness of the stocks in the residents' investment portfolio increases. In order to obtain the maximum return, the residents take the initiative to increase the holdings of the stocks, and the stocks have a substitute effect on the currency, and the demand for money decreases. Conversely, if stock prices fall, economic agents increase their share of money, which will lead to an increase in the demand for money. The substitution effect will affect the long-term money demand from the $M_{1}$ and $M_{2}$ currency levels. The influence mechanism of the substitution effect of stocks is stock price $\uparrow \longrightarrow$ actively give up money to increase stock holdings $\longrightarrow$ money demand $\downarrow$ stock price $\downarrow \longrightarrow$ choose to hold more money $\longrightarrow$ money demand $\uparrow$.

In summary, stocks are through the wealth effect and other three types. The combined effect of utility has a positive effect on the money demand, while the substitution effect has a negative effect. The final impact of stocks on the money demand depends on the combined effect of the four effects. It is also necessary to consider stocks as an asset in the money demand model and conduct empirical tests.

\section{Algorithm Simulation under the Currency Combination Model Based on Deep Learning}

The concept of experience pool playback was first proposed by previous work. Deep learning requires a lot of data to adjust the parameters of the neural network during training. In reinforcement learning, there is no ready-made dataset to train the neural network. The data is generated through interaction with the environment, so learn new samples generated by the environment one by one. The method is difficult to apply to deep networks. The data generated by the interaction can be saved for future use to solve the problem of less data. The birth of the experience pool playback technology has solved this kind of problem. Experience pool playback can increase the number of samples so that multiple epochs can be used for training, achieving the purpose of multiple use of sample data. Experience pool playback is to store the sample data generated by the previous interaction with the environment and randomly extract a part of it to train the network during each training. Experience pool playback can well overcome the problem of unbalanced data distribution and improve the efficiency of data usage. Through repeated use of the previous samples to explore and learn the environment, the problem of only learning the latest sample data in the past is well avoided. When the experience pool capacity reaches the set maximum value, the new sample data will replace the oldest sample data, thus ensuring that the probability of the sample data being selected is similar.

With the introduction of the experience pool playback function, although the network input data needs to be continuous, small-batch training becomes feasible. Different from the previous deep reinforcement learning experience pool sampling, the previous sampling data is discrete and disorderly. In this plan, the data points in the batch must be arranged in time series. Therefore, even if most of the smallbatch data of two different periods are overlapping data, they are considered different and effective. As shown in Figure 6, each batch has $n$ samples of data; then, $(\mathrm{tb}, \mathrm{tb}+n)$ and $(\mathrm{tb}+1, \mathrm{tb}+n+1)$ are valid different batches. When the stock price rises, the attractiveness of the stocks in the residents' investment portfolio increases. In order to obtain the maximum return, the residents take the initiative to increase the holdings of the stocks, and the stocks have a substitute effect on the currency, and the demand for money decreases. Conversely, if stock prices fall, economic agents increase their share of money, which will lead to an increase in the demand for money. The substitution effect will affect the long-term money demand from the $M_{1}$ and $M_{2}$ currency levels.

Using the above idea, as shown in Figure 7, the price matrix of size $[20,24,3]$ is input into the network first through the pointwise convolution operation, using $1 \times 1$ convolution kernel and ReLu activation function to perform three types of input information fusion and processing of currency attributes, and then the improved depthwise convolution operation is used to process the different currencies of each feature map and the data information of each currency for a period of time to obtain two sets of features of size $[20,24,3]$. Then, concatenate the two sets of feature maps and use a typical $3 \times 3$ convolution kernel to perform convolution and $1 \times 2$ average pooling operations to obtain a feature map of size $[20,12,6]$. Then, use a $1 \times 12$ convolution kernel to compress the feature map into a feature vector of length 20 , and set the number of convolution kernels to 12 to get 12 one-dimensional feature maps. The following network structure is the same as the previous one. 


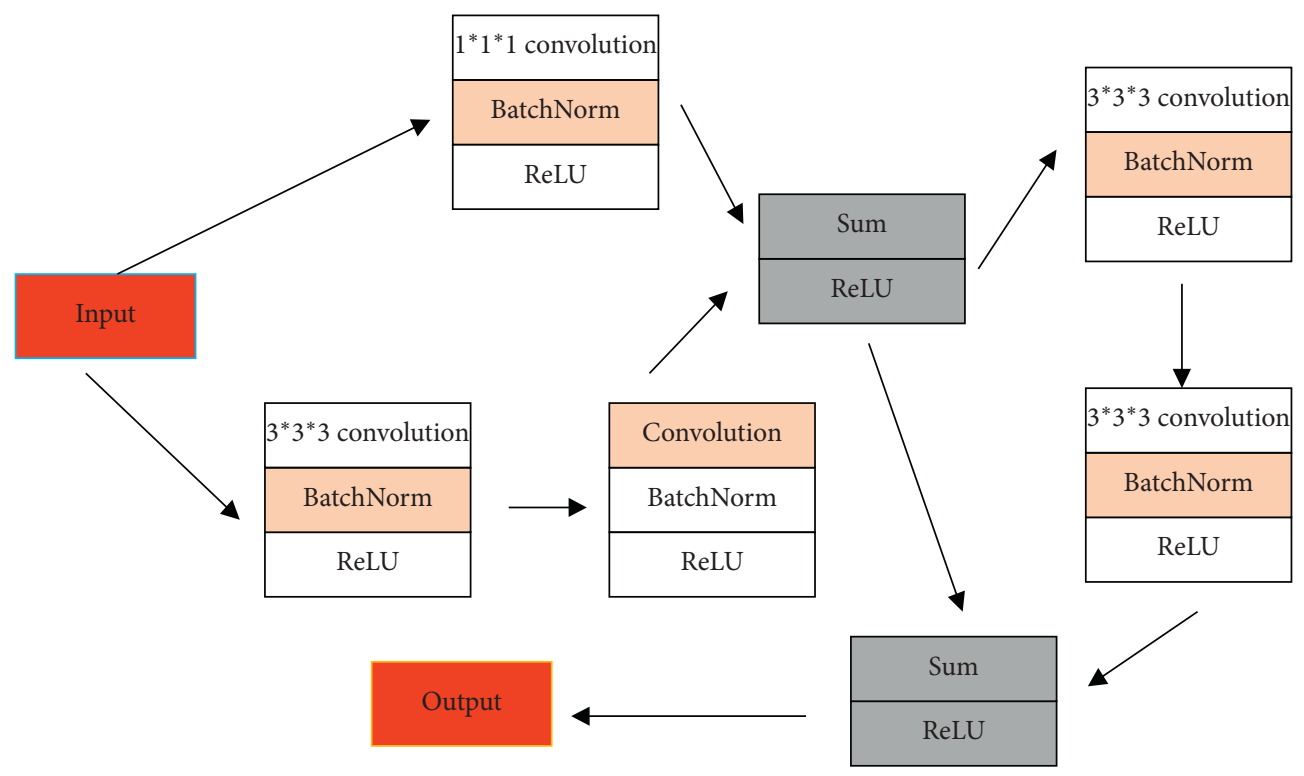

FIgURE 6: Experience pool theory.

Asset portfolio effect: regarding currency as an asset, its rate of return is a negative inflation rate, which is $a$. When the volatility of stock prices increases, the risk of holding stocks increases, and the risk of the original investment portfolio expands. Under the circumstance that the residents' risk appetite does not change, the residents will spontaneously increase the proportion of lower-risk assets in the investment portfolio to offset the risk, that is, to increase the amount of money held in the hand, which increases the demand for money. When the volatility of stock prices decreases, the risk of holding stocks decreases, and the risk level of the original investment portfolio decreases. Under the circumstance that the risk appetite does not change, residents will spontaneously increase the riskiness of the investment portfolio. The proportion of assets to increase income.

DN represents the number of days during which the return has shown negative growth during the backtest period. $\mathrm{SR}$ is an indicator that takes into account the profit factor and also the risk factor. To a certain extent, it reflects the extent to which the unit's risk fund net value growth rate is higher than the risk-free interest rate. If the Sharpe ratio is greater than zero, it indicates that the fund's risk-free rate of return has been exceeded by its average net value growth rate during the measurement period. The smaller the Sharpe ratio, the lower the return of the fund's unit risk. As shown in Figure 8, the comparison chart shows the portfolio value backtest results of the CNN and several other traditional methods during the time period from December 4, 2016, to February 1, 2017. This time, 20 for a currency asset, the data are sampled at 20 time intervals in the experimental result curve, that is, at an interval of 10 hours. Traditional portfolio strategy algorithms are follow-up strategy. The final portfolio value of CNN's strategic network has reached more than 24 or 10 , which is much higher than other traditional portfolio strategy methods. The asset selection behavior of microentities is the use of wealth

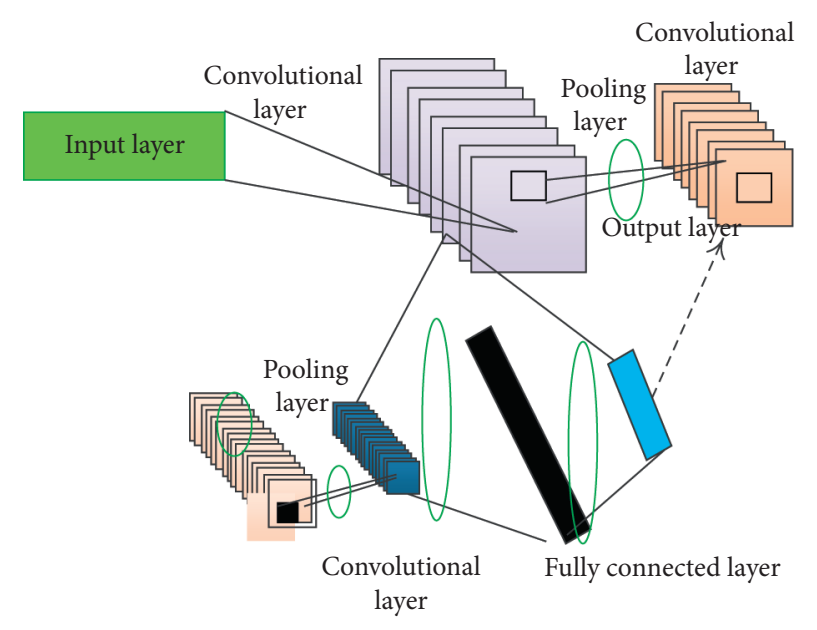

Figure 7: Improved deep separable convolutional network model.

for the purposes of preservation and profit generation. Therefore, there are three directions for residents to use wealth. One is to buy profit-generating financial assets, the other is to purchase assets with the characteristics of value preservation, and the third is to hold them in currency. Among them, profit-generating financial assets are financial assets such as bonds, stocks, and options. Assets with hedging properties mainly refer to real estate. Starting from my country's current economic conditions, the nonmonetary assets held by residents are mainly stocks and real estate. Therefore, this article only considers three assets: currency, stocks, and real estate (the currency here is defined as a narrow currency $M_{1}$, that is, cash in circulation plus savings deposits.). Country's microsubjects will choose the asset portfolio of currencies, stocks, and real estate based on the principle of maximizing utility under the established risk preference. Among them, the two assets of stocks and real 


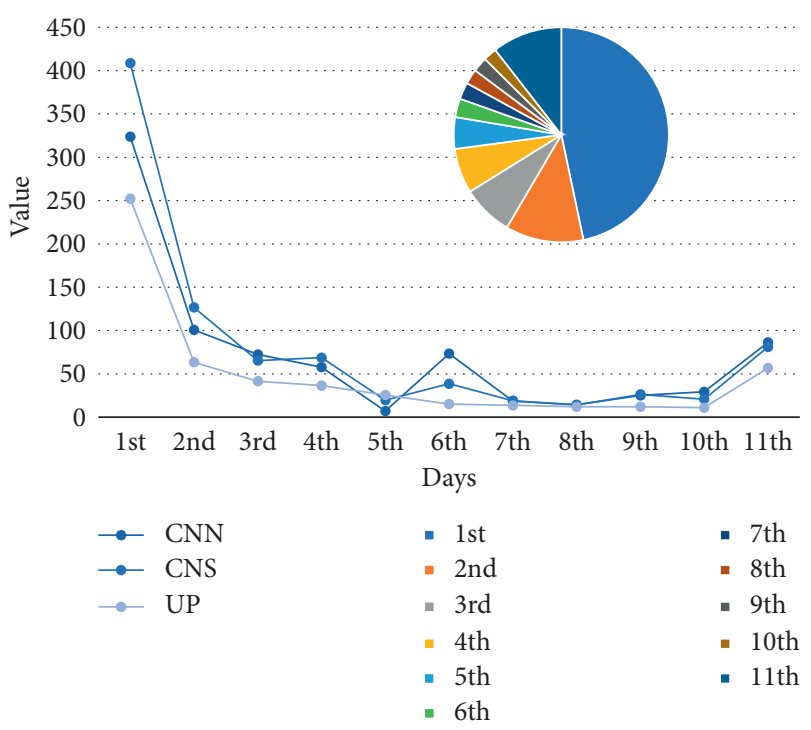

FIGURE 8: Comparison of backtesting between the CNN and traditional methods in a specific time period.

estate are special because they have the characteristics of the virtual economy. The RMR method is relatively effective, and the effects of the two follow-up strategies are not very satisfactory.

\section{Conclusion}

This paper uses the asset selection of microentities as the microfoundation to establish a money demand model to explain its economic significance. And based on the money demand model established, a dynamic equilibrium model of the money market was established, and the stability of the dynamic equilibrium point of the money market was verified through mathematical deduction. Based on the dynamic equilibrium model of the money market, the impact of money supply was analyzed. Dynamic influence: in order to verify the correctness of the aforementioned theory, this paper conducts an empirical analysis. Through cointegration analysis and the vector error correction model (VECM model), the correctness and applicability of the established money demand model are verified, and money demand, total social wealth, spreads between expected stock returns and interest rates, and real estate expectations are found. There is a long-term equilibrium relationship between the rate of return and the interest rate. The total amount of social wealth, the expected rate of return on stocks, and the interest rate spread will have an impact on the money demand in the short term.

\section{Data Availability}

The data used to support the findings of this study are available upon request to the author.

\section{Conflicts of Interest}

The author declares that there are no conflicts of interest.

\section{References}

[1] M. U. Ozmen and E. Yilmaz, "Co-movement of exchange rates with interest rate differential, risk premium and FED policy in "fragile economies,"” Emerging Markets Review, vol. 33, pp. 173-188, 2017.

[2] P. R. Bergin, R. Glick, and J.-L. Wu, “"Conditional PPP” and real exchange rate convergence in the euro area," Journal of International Money and Finance, vol. 73, pp. 78-92, 2017.

[3] S.-H. Kim, S. Moon, and C. Velasco, "Delayed overshooting: it's an 80s puzzle?" Journal of Political Economy, vol. 125, no. 5, pp. 1570-1598, 2017.

[4] S. Gopalan and R. S. Rajan, "Does foreign bank presence affect interest rate pass-through in emerging and developing economies?" Journal of Macroeconomics, vol. 54, pp. 373-392, 2017.

[5] H. Lustig and A. Verdelhan, "Does incomplete spanning in international financial markets help to explain exchange rates?" American Economic Review, vol. 109, no. 6, pp. 2208-2244, 2019.

[6] B. D. Kruskovic, "Exchange rate and interest rate in the monetary policy reaction function," Journal of Central Banking Theory and Practice, vol. 6, no. 1, pp. 55-86, 2017.

[7] A. Hameed and A. K. Rose, "Exchange rate behaviour with negative interest rates: some early negative observations," Pacific Economic Review, vol. 23, no. 1, pp. 27-42, 2018.

[8] M. Amador, J. Bianchi, L. Bocola, and F. Perri, "Exchange rate policies at the zero lower bound," The Review of Economic Studies, vol. 87, no. 4, pp. 1605-1645, 2020.

[9] Y.-W. Cheung, M. D. Chinn, A. G. Pascual, and Y. Zhang, "Exchange rate prediction redux: new models, new data, new currencies," Journal of International Money and Finance, vol. 95, pp. 332-362, 2019.

[10] F. Parlapiano, V. Alexeev, and M. Dungey, "Exchange rate risk exposure and the value of European firms," The European Journal of Finance, vol. 23, no. 2, pp. 111-129, 2017.

[11] D. Dimitriou, D. Kenourgios, and T. Simos, "Financial crises, exchange rate linkages and uncovered interest parity: evidence from G7 markets," Economic Modelling, vol. 66, pp. 112-120, 2017.

[12] T. A. Hassan and R. C. Mano, "Forward and spot exchange rates in a multi-currency world," The Quarterly Journal of Economics, vol. 134, no. 1, pp. 397-450, 2019.

[13] T. Basse, C. Wegener, and F. Kunze, "Government bond yields in Germany and Spain-empirical evidence from better days," Quantitative Finance, vol. 18, no. 5, pp. 827-835, 2018.

[14] S. Bosi, P. Fontaine, and C. Le Van, "How to determine exchange rates under risk neutrality: a note," Economics Letters, vol. 157, pp. 92-96, 2017.

[15] D. Coulibaly and H. Kempf, "Inflation targeting and the forward bias puzzle in emerging countries," Journal of International Money and Finance, vol. 90, no. 90, pp. 19-33, 2019.

[16] T. A. Maurer, T.-D. Tô, and N.-K. Tran, "Pricing risks across currency denominations," Management Science, vol. 65, no. 12, pp. 5308-5336, 2019.

[17] L. Kremens and I. Martin, "The quanto theory of exchange rates," American Economic Review, vol. 109, no. 3, pp. 810-843, 2019.

[18] S. Hu and A. Zhu, "Risk-minimizing pricing and hedging foreign currency options under regime-switching jump-diffusion models," Communications in Statistics-Theory and Methods, vol. 46, no. 4, pp. 1821-1842, 2017. 
[19] L. F. Husted, J. H. Rogers, and B. Sun, "Uncertainty, currency excess returns, and risk reversals," Journal of International Money and Finance, vol. 88, pp. 228-241, 2018.

[20] C. Engel, D. Lee, C. Liu, C. Liu, and S. P. Y. Wu, “The uncovered interest parity puzzle, exchange rate forecasting, and Taylor rules," Journal of International Money and Finance, vol. 95, pp. 317-331, 2019.

[21] M. Ames, G. Bagnarosa, and G. W. Peters, "Violations of uncovered interest rate parity and international exchange rate dependences," Journal of International Money and Finance, vol. 73, pp. 162-187, 2017. 